\title{
Reseach Paper: The Relationship Between Quality of Work Life and Organizational Commitment of Iranian Emergency Nurses
}

\author{
Reza Hashempour $^{1}$ (D), Hasan Hosseinpour Ghahremanlou², Sina Etemadi ${ }^{3 *}$ (D), Mohsen Poursadeghiyan ${ }^{4,5}$ \\ 1. Department of Health Management and Economics, School of Public Health, Tehran University of Medical Sciences, Tehran, Iran. \\ 2. Department of Epidemiology and Biostatistics, School of Public Health, Tehran University of Medical Sciences, Tehran, Iran \\ 3. Department of Health Management and Economics, Faculty of Management and Medical Information, Kerman University of Medical Sciences, \\ Kerman, Iran. \\ 4. Pediatric Neurorehabilitation Research Center, Department of Ergonomics, University of Social Welfare and Rehabilitation Sciences, Tehran, Iran. \\ 5. Health in Emergency and Disaster Research Center, University of Social Welfare and Rehabilitation Sciences, Tehran, Iran.
}

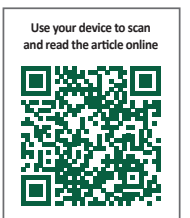

Citation Hashempour R, Hosseinpour Ghahremanlou H, Etemadi S, Poursadeghiyan M. The Relationship Between Quality of Work Life and Organizational Commitment of Iranian Emergency Nurses. Health in Emergencies and Disasters Quarterly. 2018; 4(1):49-54. http://dx.doi.org/10.32598/hdq.4.1.49

: http://dx.doi.org/10.32598/hdq.4.1.49

\section{(c) (i) (5)}

Funding: See Page 53

Article info:

Received: 23 May 2018

Accepted: 25 Aug 2018

Available Online: 01 Oct 2018

\section{Keywords:}

Quality of work life,

Organizational commitment, Job satisfaction, Hospital, Nurse

\section{ABSTRACT}

Background: Quality of work life depends on a combination of variables in the work environment thathas an importantimpact on organizational commitment, work participation, and job performance. Therefore, measuring two variables of quality of work life and organizational commitment is important for all employees of organizations, including emergency nurses, who are important members of the health service community. This study aimed to determine the relationship between quality of work life and organizational commitment among Iranian emergency nurses.

Materials and Methods: A descriptive and correlational study was conducted in 2016. The study population included all emergency nurses working in one of the hospitals of Kerman Province, Iran. The data collection tool was the personal and occupational questionnaire, Walton quality of work life questionnaire, and Allen and Meier organizational commitment questionnaire. Data analysis was performed by using descriptive tests, the Pearson correlation and ANOVA statistics tests in SPSS V. 23.

Results: The results showed that the quality of work life has a positive and significant relationship ( $\mathrm{r}=0.49, \mathrm{P}=0.017$ ) with organizational commitment. More specifically, quality of work life is related to emotional commitment ( $\mathrm{r}=0.44, \mathrm{P}=0.001)$, normative commitment $(\mathrm{r}=0.40, \mathrm{P}=0.003)$ and continuous commitment $(\mathrm{r}=0.33, \mathrm{P}=0.015)$.

Conclusion: Since the higher quality of work life brings more commitment for employees, managers can improve the essential components of working life quality of nurses by adopting appropriate solutions, and providing the necessary conditions for improving the quality of service provision and productivity.

* Corresponding Author:

Sina Etemadi, BSC.

Address: Department of Health Management and Economics, Faculty of Management and Medical Information, Kerman University of Medical

Sciences, Kerman, Iran

E-mail: sina.etemadi007@gmail.com 


\section{Introduction}

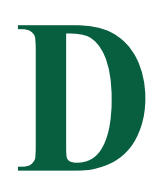

isasters can overwhelm the health care system. One of the most important components of this system is emergency departments which is the front line in hospitals and emergency nurses play an important role in providing these crucial services. Emergency nurses must have the necessary experiences and skills to manage emergency situations [1]. The nurses always play a vital role in managing disasters [2].

It is necessary to consider not only the diverse and complicated dimensions that create individual, group, and organizational needs and desires, but also individual and group differences in terms of high quality working conditions, when dealing with keeping good employees. One of these effective factors is the quality of work life. The quality of work life program includes any improvement in the organizational culture that supports the growth and development of employees in the organization [3].

The term "quality of work life" has been widely-used in recent years. However, there is little agreement on the meaning of the term, while at least two of the most common definitions are the followings. First, the quality of work life refers to a set of outcomes for employees such as job satisfaction, growth opportunities, psychological issues, occupational security, the low level of accidents, and human relations between the employer and employees. Second, the quality of working life also refers to a set of work or organizational functions such as participatory management, job enrichment, and safe working conditions $[4,5]$.

The quality of work life is a set of real working conditions in an organization, such as fair and adequate pay, safe and hygienic working environments, equal opportunities for continued growth and security, organizational legality, social affiliation in working life, overall living space, social unity, and development of human capabilities [6]. Thus, the value system of the quality of work life considers the investing in individuals as the most important variable in the strategic management, put it differently, the fulfillment of staff needs will lead to the improvement and long-term performance of the organization [7]. High quality of work life is necessary to retain the personnel in hospital with job satisfaction [8-10].

Organizational commitment is also another variable that has been very important in organizational behavior, and it represents a motive that requires an individual to stay in the organization and to do something with the commitment to achieve the organizational goals [11].
Organizational commitment is an important occupational and organizational attitude that has drawn researchers' interests in organizational behavior courses in recent years because it is an important variable in understanding employee's behavior. Organizational commitment can be defined simply as loyalties to the values and goals of the organization, sense of belonging, dependency, and moral obligation to stay in the organization [12].

Commitment of human resources to the organization reduces absenteeism, delay and displacement; significantly increases the organization's performance, employees' mental vitality, better manifestation of the organization's transcendental goals, and achievement of individual goals [13]. Various factors affect emotional commitment of employees: individual characteristics such as age, service record, level of education, gender, marital status; job characteristics such as occupational field, conflict between job and role; structural features such as the degree of formalization and concentration in the organization, the size of the organization and the level of work experience of the person [14].

Health care jobs are among the jobs in which the two mentioned variables are significant. The goal of the health care system is to provide the physical, psychological, and social health of the people, and at the same time create an environment that the health staff can deliver higher quality and more effective services [15]. Nurses spend several hours a day in work environment, thus quality of work life and organizational commitment are two important components for this staff, and dissatisfaction of these issues affects their other roles at home and community. Since the nurses' job conditions are different and important in the countries and even in different cities, as well as the quality of work life is important in any profession and in any organizational culture and work environment, this study aimed to determine the relationship between the quality of work life and the organizational commitment of nurses working in one of the hospitals of Kerman Province, Iran.

\section{Materials and Methods}

This study was descriptive and cross-sectional and conducted in 2016. We were not allowed to select all hospitals so we have to select one hospital. The study population included all emergency nurses working in a hospital in Kerman Province. The study was done by two questionnaires, including Walton quality of work life questionnaire and Allen and Meyer's organizational commitment questionnaire. The quality of work life questionnaire included 32 questions and scored based on 
the 5-point Likert-type scale from "very little" to "very high". The components of this questionnaire included "fair and adequate payment", "a safe and healthy work environment", "providing opportunities for continued growth and security", "organizational legality", "social affiliation of working life", "overall living space", "social integration and social cohesion," and "development of human capabilities". The validity of the questionnaire was well evaluated by using the views of the experts. Rahimi (2006) stated that the reliability of the test was 0.85 [16] and in this study it was calculated as 0.77 by Cronbach test.

The 24 questions of organizational commitment questionnaire had 7 options, including "very agreeable", "fairly agreeable", "slightly agree", "I have no idea", "slightly disagree", "relatively disagree", and "totally disagree". It also comprised three dimensions of emotional, continuous, and normative, whose validity was confirmed by the experts and its reliability was estimated as 0.83 in Yaghoubi study (2010) by calculating Cornbrash alpha value. In this study, it was calculated as 0.76 by Cornbrash alpha test [17].

In this study, we used descriptive statistics (frequency, mean and standard deviation) were used. In addition, the data were analyzed by using Shapiro-Wilk test. Since the distribution of data was normal, the Pearson correlation test was used to measure the correlation between quality of work life dimensions and organizational commitment. To determine the relationship between the qualities of work life score, organizational commitment and individual characteristics of emergency nurses, the Spearman test and ANOVA were used. The obtained data were analyzed in SPSS V. 23.

\section{Results}

Based on the results, most nurses were between 30 and 40 years old. Most of the subjects ( $n=46,90.2 \%$ ) had a bachelor's degree. Also, most nurses had less than 5 years' work experience (41.2\%) (Table 1). The Mean \pm SD of working life quality of nurses was $89.36 \pm 15.9$. The Mean \pm SD of organizational commitment for nurses was $99.93 \pm 13.14$. The results of the Pearson test indicate a positive and significant relationship between quality of work life and organizational commitment $(\mathrm{r}=0.49$, $\mathrm{P}=0.017$ ) (Table 2).

The relationship between the quality of work life and emotional commitment of employees was examined by the Pearson correlation test (Table 2). The results indi-

Table 1. Personal and professional characteristics of study nurses

\begin{tabular}{|c|c|c|c|}
\hline \multirow[t]{2}{*}{ Variables } & Range & No. & $\%$ \\
\hline & $20-30$ & 24 & 47.9 \\
\hline \multirow[t]{4}{*}{ Age, $y$} & $30-40$ & 25 & 49 \\
\hline & $40-50$ & 2 & 3.9 \\
\hline & Total & 51 & 100 \\
\hline & Associate degree & 2 & 3.9 \\
\hline \multirow[t]{5}{*}{ Educational lev } & Bachelor degree & 46 & 90.2 \\
\hline & Master degree & 3 & 5.9 \\
\hline & Total & 51 & 100 \\
\hline & Less than 5 years & 21 & 41.2 \\
\hline & 5 to 10 years & 16 & 31.4 \\
\hline \multicolumn{4}{|c|}{ Working background } \\
\hline & 10 to 15 years & 10 & 19.6 \\
\hline & 15 to 20 years & 4 & 7.8 \\
\hline \multicolumn{2}{|c|}{ Total } & 51 & 100 \\
\hline
\end{tabular}


Table 2. The Pearson correlation coefficient between quality of work life and organizational commitment

\begin{tabular}{|c|c|c|c|c|c|c|c|c|}
\hline \multirow{3}{*}{ Variable } & \multicolumn{8}{|c|}{ Commitments } \\
\hline & \multicolumn{2}{|c|}{ Organizational } & \multicolumn{2}{|c|}{ Emotional } & \multicolumn{2}{|c|}{ Continuous } & \multicolumn{2}{|c|}{ Normative } \\
\hline & Correlation & $\mathbf{P}$ & Correlation & $\mathbf{P}$ & Correlation & $\mathbf{P}$ & Correlation & $\mathbf{P}$ \\
\hline Quality of work & 0.49 & 0.017 & 0.44 & 0.001 & 0.33 & 0.015 & 0.40 & 0.003 \\
\hline
\end{tabular}

Table 3. Relationship between quality of work life and organizational commitment with personal and professional information

\begin{tabular}{ccccccc}
\hline Correlation & Age & $\mathbf{P}$ & Service Record & $\mathbf{P}$ & Educational Level & $\mathbf{P}$ \\
\hline Quality of work life & 0.080 & 0.57 & -0.082 & 0.56 & -0.017 & 0.90 \\
Organizational commitment & 0.027 & 0.85 & -0.093 & 0.51 & -0.009 & 0.94 \\
\hline & & & & $\begin{array}{c}\text { |llealth in } \\
\text { Emergencies and [D]isasters [Oluarterly }\end{array}$
\end{tabular}

cate a positive and significant relationship between quality of working life and organizational commitment. The results of the Pearson correlation test between quality of work life and continuous commitment (Table 2) indicate a positive significant relationship between quality of work life and continuous commitment $(\mathrm{P}=0.015)$. Also, as shown in Table 2, there is a positive and significant relationship between quality of work life and normative commitment $(\mathrm{P}=0.003)$.

According to Table 3, the relationship between quality of work life and personal and professional information (age, educational level, service record) was assessed by using the Pearson test and showed no significant relationship between these variables. In addition, the relationship between organizational commitment and personal and professional information was not significant $(\mathrm{P}>0.05)$.

\section{Discussion}

This study was conducted in a hospital in Kerman Province among emergency nurses considering crucial roles of nurses. There was a positive and significant relationship between quality of work life and organizational commitment of emergency nurses based on the finding of this study. The relationship between quality of work life and emotional commitment showed that perceptions of nurses about their quality of life can affect their feeling of psychological dependence and their identification. In other words, we can expect that nurses feel more psychologically dependent by the improvement of the quality of work life, and adapt themselves to maternity hospitals and enjoy membership. Moreover, a positive and significant relationship was shown between quality of work life and emotional commitment in this study.
Similar relationship was found in the study entitled "relationship between quality of work life and organizational commitment and its components". In this study, there was a significant relationship between different aspects of quality of work life and organizational commitment. Moreover, the Pearson correlation results showed a significant relationship between some aspects of quality of work life such as "fair and adequate pay", "equal opportunity of growth" and "continuous security and development of human ability" with emotional, normative, and continuous commitmen [18].

Another study with the title of "the effect of quality of work life on organizational commitment in security forces" reported a positive and significant relationship between different components of quality of work life and organizational commitment. Out of different characteristics of work environment, providing job security had the strongest relationship with organizational commitment [19]. In another study entitled "relationship between different components of quality of work life and organizational commitment in library's workers", there was a significant and positive relationship between different components of quality of work life and organizational commitment and these results were consistent with our results [20].

These results showed that quality of work life affects organizational commitment and we can increase organizational commitment by increasing quality of work life. Moreover increasing emotional affinity in employees and more involving them with organization goals, improving social communication networks, participating the employees in decision making, and evaluating the employee's performance in order to create job feedback 
would increase organizational commitment and subsequently improve the quality of work life [21].

In any organization, there must be a mutual commitment between employees and organizations. Personnel consider their commitment to organization's goal and organization considers their commitment to their personnel. Therefore, managers of organizations should pay special attention to the quality of work life of their employees and provide mechanisms to enhance their ability to increase the level of commitment and attachment.

\section{Conclusion}

Managers can improve the quality of work life by provisions such as providing opportunities for growth and development of staff abilities, providing conditions for employees' more engagement, promoting teamwork, planning for fair and just payment. Managers should engage in these plans as soon as possible, otherwise some adverse outcomes will ensue that could be a disaster at national level.

\section{Ethical Considerations}

\section{Compliance with ethical guidelines}

The addresses and names of the samples were not included in our data. All ethical principles were considered in this article. The participants were informed about the purpose of the research. They were also guaranteed about the privacy of their information; Moreover, They were free to whether leave or stay the study whenever they wish.

\section{Funding}

This research did not receive any specific grant from funding agencies in the public, commercial, or not-forprofit sectors.

\section{Authors contributions}

The authors contributions is as follows: Conceptualization: Mohsen Poursadeghian, Reza Hashempour; Methodology: Sina Etemadi; Investigation: Hasan Hosseinpour Ghahremanlou; Writing-original draft: Reza Hashempour, Hasan Hosseinpour Ghahremanlou; Writing-review \& editing: Reza Hashempour, Sina Etemadi; Supervision: Mohsen Poursadeghian; and Analysis: Reza Hashempour, Hasan Hosseinpour Ghahremanlou.

\section{Conflict of interest}

The authors declared no conflict of interest.

\section{References}

[1] Hammad KS, Arbon P, Gebbie KM. Emergency nurses and disaster response: An exploration of South Australian emergency nurses' knowledge and perceptions of their roles in disaster response. Australasian Emergency Nursing Journal. 2011; 14(2):87-94. [DOI:10.1016/j.aenj.2010.10.002]

[2] Labrague L, Hammad K, Gloe D, McEnroe-Petitte D, Fronda $\mathrm{D}$, Obeidat $\mathrm{A}$, et al. Disaster preparedness among nurses: A systematic review of literature. International Nursing Review. 2018; 65(1):41-53. [DOI:10.1111/inr.12369] [PMID]

[3] Dockel A, Basson JS, Coetzee M. The effect of retention factors on organisational Commitment: An investigation of high technology employees. SA Journal of Human Resource Management. 2006; 4(2):a91. [DOI:10.4102/sajhrm.v4i2.91]

[4] Rudaki M. [Dynamic analysis of quality of work life (Persian)] [MSc. thesis]. Tehran: Islamic Azad University, Tehran South Branch; 2008

[5] Abbasi M, Zakerian A, Mehri A, Poursadeghiyan M, Dinarvand N, Akbarzadeh A, et al. Investigation into effects of work-related quality of life and some related factors on cognitive failures among nurses. International Journal of Occupational Safety and Ergonomics. 2017; 23(3):386-92. [D OI:10.1080/10803548.2016.1216991] [PMID]

[6] Vahidi Roodposhti M, PoorNaserani S, Hashemi Z, Mohammadi Choolabi M, Noghreh Chafi M, Aghajan Khah Sh, et al. The impact of employee quality of work life on customer relationship management. Interdisciplinary Journal of Contemporary Research in Business. 2013; 4(11):730-7.

[7] Richard B. Predicting the organizational commitment of marketing education and health occupations education teachers be work related rewards. Journal of Industrial Teacher Education. 2007; 32(1):1-14.

[8] Abbasi M, Zakerian A, Mehri A, Poursadeghiyan M, Dinarvand N, Akbarzadeh A, et al. Investigation into effects of work-related quality of life and some related factors on cognitive failures among nurses. International Journal of Occupational Safety and Ergonomics. 2017; 23(3):386-92. [D OI:10.1080/10803548.2016.1216991] [PMID]

[9] Poursadeghiyan M, Abbasi M, Mehri A, Hami M, Raei MM Ebrahimi MH.Relationship between job stress and anxiety, depression and job satisfaction in nurses in Iran. The Social Science. 2016; 11(9):2349-55

[10] Moradi S, Farahnaki Z, Akbarzadeh A, Gharagozlou F, Pournajaf A, Abbasi AM, et al. Relationship between shift work and Job satisfaction among nurses: A cross-sectional study. International Journal of Hospital Research. 2014; 3(2):63-8.

[11] Meyer JP, Herscovitch L. Commitment in the workplace: Toward a general model, human resource management review. 2001; 11(3):299-326. 
[12] Asadi B. [Relationship between participatory management and occupational attitudes of the national Olympic and Paralympic academy staff (Persian)] [MSc. thesis]. Amol: North University; 2009.

[13] Lee J, Peccei R. Perceived organizational support and affective commitment: The mediating role of organization-based selfesteem in the context of job insecurity. Journal of Organizational Behavior. 2007; 28(6):661-685. [DOI:10.1002/job.431]

[14] Ashrafi B. [Studying factors effecting organizational commitment of the mangers of eastern alborz coal company (Persian)] [MSc. thesis]. Tehran: Tarbiat Modares University; 1995.

[15] Hadizadeh Talasaz Z, Nourani Saadoldin Sh, Shakeri MT. The relationship between Job Satisfaction and job performance among midwives working in healthcare centers of Mashhad, Iran. Journal of Midwifery and Reproductive Health. 2014; 2(3):157-64. [DOI: 10.22038/JMRH.2014.2623]

[16] Rahimi R. [Surveying the quality of work life of faculty members of Isfahan University (Persian)] [MSc. thesis]. Isfahan: Isfahan University; 2006.

[17] Yaghoubi M, Karimi S, Javadi M, Hassanzadeh A. [A survey on relationship between Job stress and three dimensions of organization commitment among nursing managers (Persian)]. Scientific Journal of Hamadan Nursing and Midwifery Faculty. 2010; 18(1):5-15.

[18] Ali M, Neda M, Mohsen G. [Relationship between quality of work life dimensions with organizational commitment and its components (Persian)]. Journal of Social Psychology. 2011; 6(20):41-53.

[19] Ghari m, Abdolalipour G, Ghobadi A. The role of quality of work life in the organizational commitment of the staff of the university of police office. Police Studies. 2010; 6(2):177-93.

[20] Fathollahzadeh F. [A survey on the relationship between the components of quality of work life with organizational commitment among librarians of public libraries of West Azerbaijan province(Persian)]. Quarterly Journal of Knowledge and Information Management. 2016; 2(4):63-70.

[21] Massah H, Samavatyan H. [The relationships between demographic variables, emotional intelligence and types of organizational commitment with quality of work life (Case study: Oil company of central areas of Iran) (Persian)]. Psychology. 2012; 15(4):336-52. 